\title{
PRIMARY IMMUNOBLASTIC B-CELL LYMPHOMA OF THE STERNUM
}

\author{
Peter L. Faries, MD, ${ }^{\mathrm{a}}$ Marcus D'Ayala, MD, ${ }^{a}$ and Gil Hauer Santos, MD, ${ }^{\mathrm{b}}$ Bronx, N.Y.
}

A 38-year-old man was referred to us with a painful sternal mass. On examination a firm, fixed, tender $3 \times 3$ $\mathrm{cm}$ sternal mass was present at the level of the third rib. Roentgenographic and computed tomographic studies of the chest demonstrated a $2.5 \times 3 \times 3 \mathrm{~cm}$ lytic mass originating in the right side of the sternum at the level of the third rib (Fig. 1). No extension into the mediastinum and no mediastinal or hilar adenopathy were present. The lung fields were clear and the large airways were without compromise. Computed tomographic scans of the head, abdomen, and pelvis, a radionuclide bone scan, and bronchoscopic examination demonstrated no evidence of malignant disease at other sites.

At operation an incisional biopsy with frozen section demonstrated large cell lymphoma, and the patient underwent surgical resection of the mass for palliation of his pain and tumor debulking. The lower end of the manubrium and the sternum were resected from the first to the fourth intercostal spaces with the second and third costal cartilages bilaterally. The tumor was excised without dissection of the mediastinum. Prosthetic reconstruction was unnecessary. The pectoralis muscles and overlying skin were mobilized bilaterally and used to repair the soft tissue defect. The patient was extubated in the operating room. He had an uneventful recovery and was discharged from the hospital on the sixth postoperative day. At the time of discharge he had no difficulty in mobilizing the chest wall for gas exchange satisfactory for usual activity.

Pathologic examination of the specimen demonstrated a soft pink-tan lesion originating in the sternum, replacing the trabecular bone and thinning the cortical bone. The tumor did not extend to the mediastinum. Microscopic evaluation demonstrated sheets of malignant, highly pleomorphic lymphocytes within the sternal mass (Fig. 2). Extensive necrosis and a high mitotic rate were present, and plasmacytoid and polymorphous immunoblastic features of lymphoma were seen. Immunohistochemical analysis was positive for lymphocyte (LCA) and B-cell (L26) markers and negative for T-cell (UCHL1) and neuroendocrine ( $\mathrm{S} 100$, chromogranin) markers, confirming the diagnosis of a non-Hodgkin's immunoblastic B-cell lymphoma originating in the sternum. The patient re-

From the Departments of Surgery ${ }^{a}$ and Thoracic Surgery, ${ }^{b}$ Montefiore Medical Center, Albert Einstein College of Medicine, Bronx, N.Y.

Received for publication Feb. 25, 1997; accepted for publication Feb. 26, 1997.

Address for reprints: Peter L. Faries, MD, Department of Surgery, First Floor Gold Zone, Montefiore Medical Center, 111 East 210th St., Bronx, NY 10467.

J Thorac Cardiovasc Surg 1997;114:684-5

Copyright (C) 1997 by Mosby-Year Book, Inc.

$0022-5223 / 97 \$ 5.00+0 \quad \mathbf{1 2 / 5 4 / 8 1 5 9 0}$

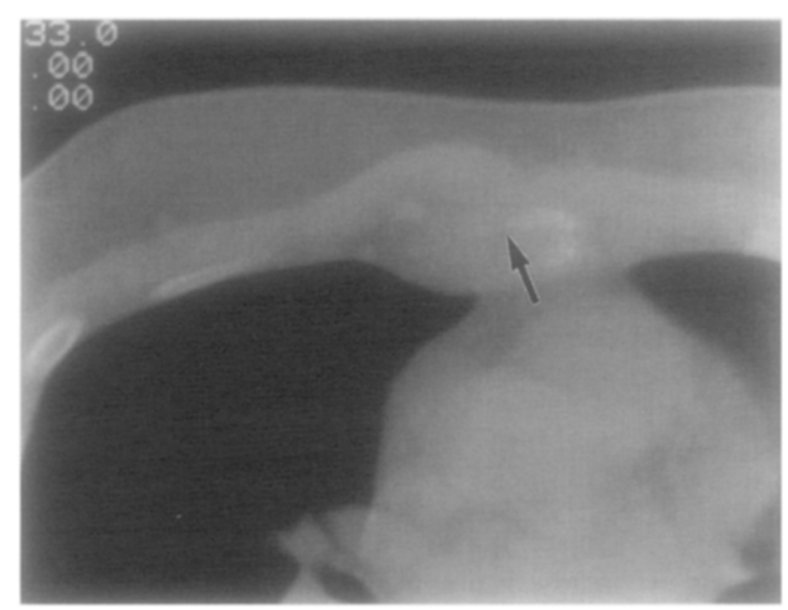

Fig. 1. Computed tomographic scan of sternal lymphoma. Lytic destruction of the right sternum is evident (arrow). No calcification or invasion of the mediastinum is present.

ceived six cycles of cyclophosphamide, doxorubicin, vincristine, and prednisone and is well with no evidence of active disease 2 years after the operation.

The management of sternal tumors may be complex and is typically directed by the histologic nature of the tumor, its location, and the extent of involvement of the sternum and adjoining structures. The majority of sternal tumors are malignant. Primary solid and small cell tumors, as well as metastatic lesions, have been reported. ${ }^{1}$

Both Hodgkin's disease and non-Hodgkin's lymphoma involving the sternum and chest wall have been described. Frequently the malignancy originates within lymph nodes of the mediastinum or internal thoracic chain and invades the chest wall through direct extension. Mediastinal adenopathy occurs frequently in Hodgkin's disease but is unusual in non-Hodgkin's lymphoma, in which endobronchial and diffuse interstitial involvement occur. Isolated chest wall masses are distinctly uncommon and are usually a manifestation of large cell non-Hodgkin's lymphoma. One case of localized Hodgkin's disease that was detected as a sternal tumor and required total sternectomy plus reconstruction with a Marlex mesh prosthesis (Bard Implants, Billerica, Mass.) has been reported. ${ }^{2}$ A case of non-Hodgkin's lymphoma of lymphoid progenitor cell origin appearing as a lytic sternal lesion has also been described. ${ }^{3}$ That patient was treated with radiation and chemotherapy but died 7 months after the initial diagnosis. Six cases of high-grade malignant lymphoma of the sternum have also been reported. Two of the patients were treated with sternectomy, three with radiation, and one with chemotherapy, with an overall 10-year survival of 


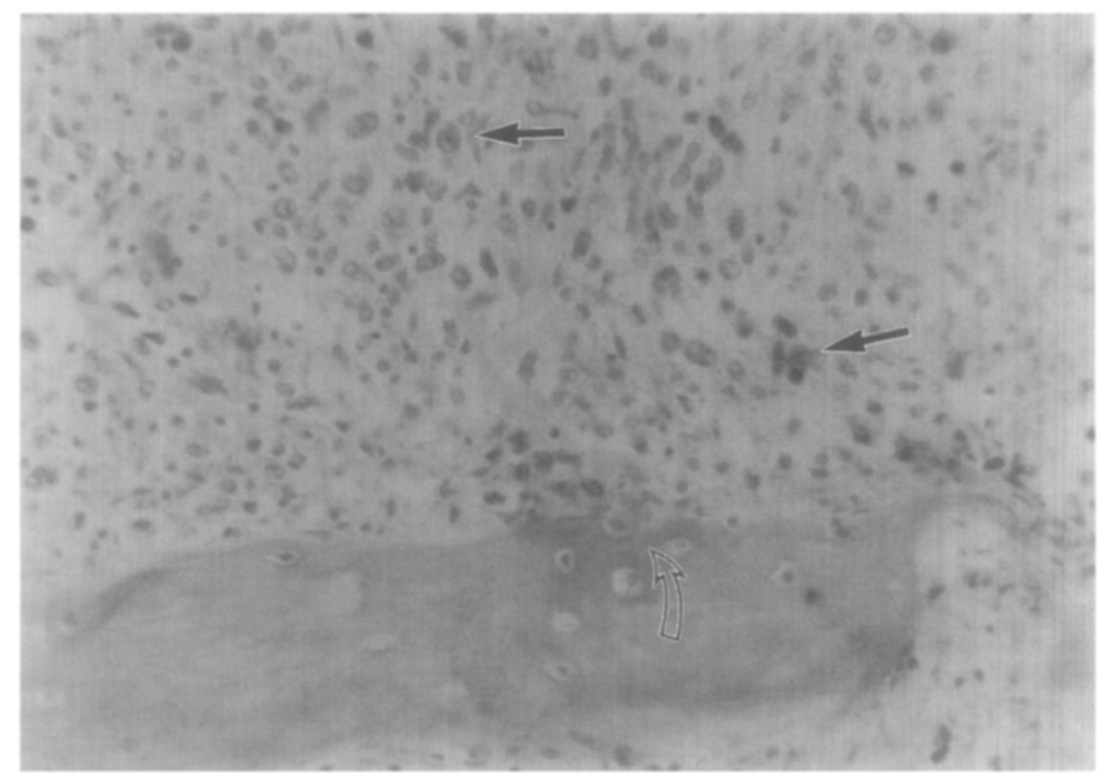

Fig. 2. Histologic section of the sternal lymphoma. Malignant, highly pleomorphic lymphocytes (black arrows) are seen invading the trabecular bone (open arrow) of the sternum. A high miotic rate and immunoblastic features are present (hematoxylin and eosin stain; original magnification $\times 100$ ).

83\%. ${ }^{1}$ Non-Hodgkin's lymphoma of the anterior mediastinum with evidence of B-cell origin has also been seen, ${ }^{4}$ but no case of B-cell immunoblastic non-Hodgkin's lymphoma originating in the sternum has been reported previously.

Resection of sternal tumors with adequate surgical margins of $4 \mathrm{~cm}$ may result in substantial bony and soft tissue defects. Loss of the upper sternal body and the costal cartilages, as in this case, produces a defect that is not physiologically significant. More extensive resections including the entire sternal body or manubrium with the adjacent ribs and clavicles produce more severe deficits. Reconstruction is therefore necessary to avoid prolonged ventilatory support. ${ }^{1}$ Reconstruction after sternal resection can be performed with a variety of materials. Skin defects are frequently small and are most often covered primarily by advancing skin flaps. Larger defects may require split-thickness skin grafting or closure as part of a myocutaneous tissue flap. Underlying soft tissue defects may be closed by advancing pectoralis muscle flaps, by transposition of a free tissue graft, or by an omental flap. Prosthetic materials including polytetrafluoroethylene, methyl methacrylate, polypropylene, polyethylene, and steel mesh have all been used successfully in reconstructing sternal defects. ${ }^{5}$

\section{REFERENCES}

1. Martini N, Huvos AG, Burt ME, Heelan RT, Bains MS, McCormack PM, et al. Predictors of survival in malignant tumors of the sternum. J Thorac Cardiovasc Surg 1996;111: 96-106.

2. Arnold HS, Messe EH, D'Amato NA, Maughton JS. Localized Hodgkin's disease presenting as a sternal tumor and treated by total sternectomy. Ann Thorac Surg 1966:2:87-93.

3. Ishizawa M, Okabe $\mathrm{H}$, Matsumoto K, Hukuda S, Hodihara K, Ota S. Anaplastic large cell Ki-lymphoma with bone involvement: report of two cases. Virchows Arch 1995;427:105-10.

4. Addis BJ, Isaacson PG. Large cell lymphoma of the mediastinum: a B-cell tumor of probably thymic origin. Histopathology 1986;10:379-90.

5. McKenna RJ Jr, Mountain CF, McMurtrey MJ, Larson D, Stiles QR. Current techniques for chest wall reconstruction: expanded possibilities for treatment. Ann Thorac Surg 1988; 46:508-12. 